\title{
Pedunculated islet-cell tumour of the duodenum
}

\author{
R. P. BRITT ${ }^{1}$ \\ From the Department of Pathology, The Royal Hospital, Sheffield
}

SYNOPSIS An unusual islet-cell tumour found at necropsy in a patient who had died from a my cardial infarction is described. Of particular interest were the pedunculated nature and large sizet of the tumour. The clinical features of the case are considered. Four islet-cell tumours in the duof denum have previously been reported and it seems probable that such tumours arise in heterotopie pancreas.

\section{CASE REPORT}

The patient, a motor-coach driver of 56 years, was admitted to hospital as an emergency because of the sudden onset of severe chest pain. A diagnosis of myocardial infarction was made from the clinical features and this was confirmed by the electrocardiographic findings. He had previously been in good health apart from 'indigestion' which had been present and increasing in severity for six months. The haemoglobin on admission was $72 \%(10 \cdot 7 \mathrm{~g} / 100 \mathrm{ml}$.) and a blood film showed the features of iron deficiency.

Treatment was commenced with anticoagulants. During the ensuing 72 hours he developed the symptoms and signs of heart failure which did not respond to the usual forms of treatment. He died on the fifth day after his admission.

\section{POST-MORTEM EXAMINATION AND HISTOLOGY}

Examination of the heart revealed a recent extensive postero-septal myocardial infarct of the left ventricle. There was considerable atheroma of the coronary arteries.

Within the lumen of the second part of the duodenum and arising from the medial wall was a mucosa-covered, pedunculated mass $3.5 \times 2 \times 1$ $\mathrm{cm}$. (Fig. 1). The mucosal pedicle which permitted limited movement of the mass within the duodenum was $1.5 \mathrm{~cm}$. in length, $2 \mathrm{~cm}$. in width, and $0.5 \mathrm{~cm}$. thick (Fig. 2). The pedicle arose $7 \mathrm{~cm}$. distal to the pylorus and $2 \mathrm{~cm}$. proximal to the ampulla of Vater. The mucosal surface of the mass opposite the attachment of the pedicle showed central umbilication and several shallow ulcerated areas were present, the largest having a maximum diameter of $0.3 \mathrm{~cm}$. The mass was firm and the cut surface had a finely trabeculated appearance with a yellowish white

'Present address: Pathology Laboratory, Stoke Mandeville Hospital, Aylesbury, Bucks.

Received for publication 7 October 1965. colour. Dissection showed the mass to be surv rounded by mucosa except at the point of attachmerf of the pedicle.

No abnormalities were found in endocrine gland and there was no peptic ulceration apart from that described above.

Microscopic examination revealed that the tumou was composed of loose vascular connective tissue containing rounded collections of cells, these varying in size from $0.05 \mathrm{~mm}$. to $1 \mathrm{~mm}$. in diamete (Fig. 3). The cells were clumped together in ribborof like strands; the columns of cells thus formes varied from one to five cells in width (Fig. 49 Mitoses were infrequent in these cells and the cytoplasm contained fine granules.

Many duct-like structures were identified, line by non-ciliated columnar epithelium. The lumina of these channels were empty apart from occasiona fragments of epithelium. Most of these duct-like structures were in the region of the central umbilicas. tion, and one of the larger 'ducts' was seen to open on to the surface.

Microscopic examination confirmed the close investment of the mass by duodenal mucos? Invasion of blood vessels or other structures was not seen nor was there any other histological evtdence of malignancy.

\section{COMMENT}

The findings described are those of an islet-cet tumour presumably arising from heterotopic pare creas present in the wall of the duodenum. This striking histological resemblance between the clumps of cells in these tumours and the islets of Langerhans of normal pancreas (Laidlaw, 1938 Frantz, 1959) is clearly seen here (Fig. 3) and th finding of duct-like structures close to the 'islets' ii the tumour gave further support to this diagnosis. 


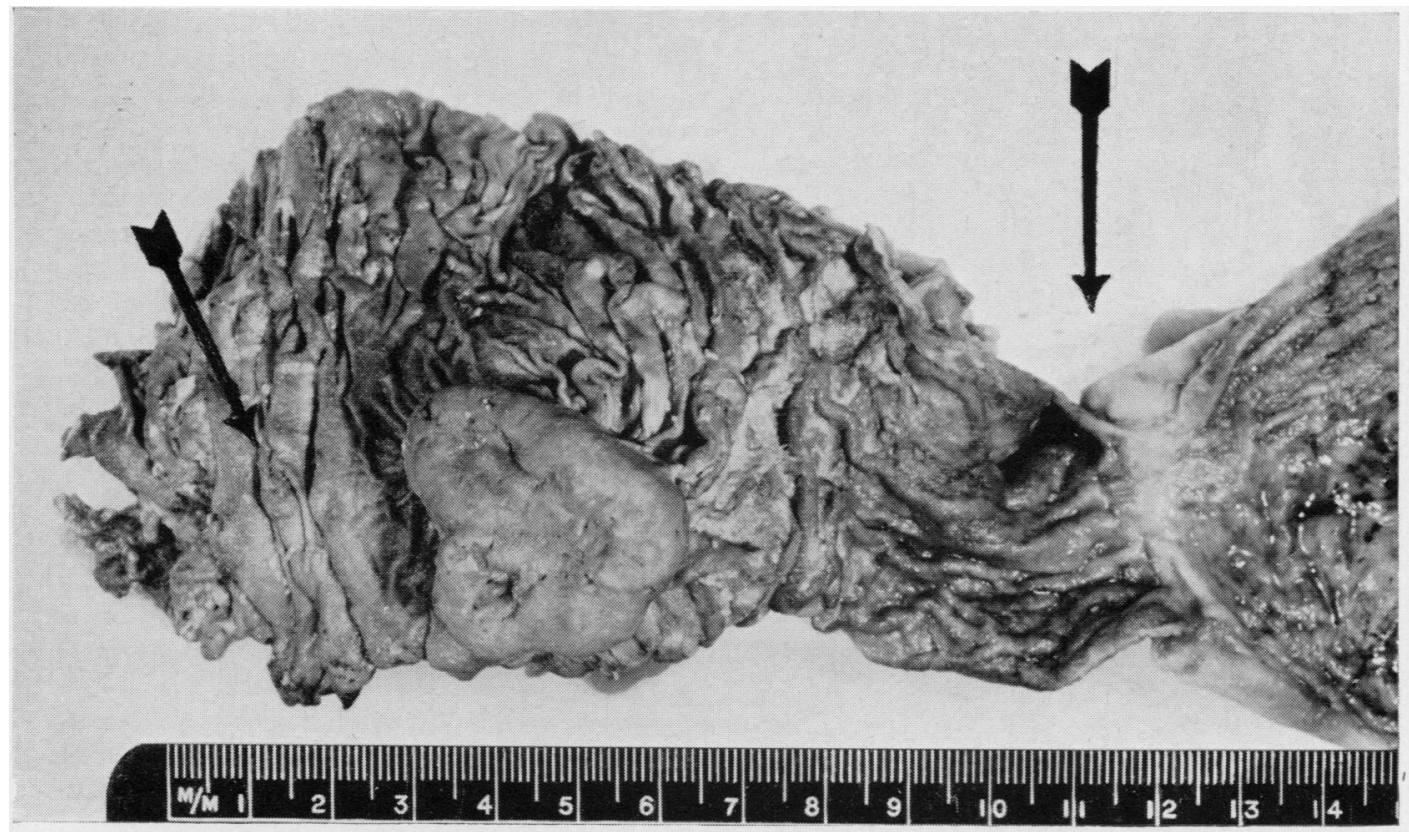

FIG. 1. Portion of stomach and proximal part of duodenum laid open to demonstrate the tumour on the opposite aspect to the attachment of the pedicle. Arrows indicate (left) the ampulla of Vater and (right) the pylorus. Actual size.

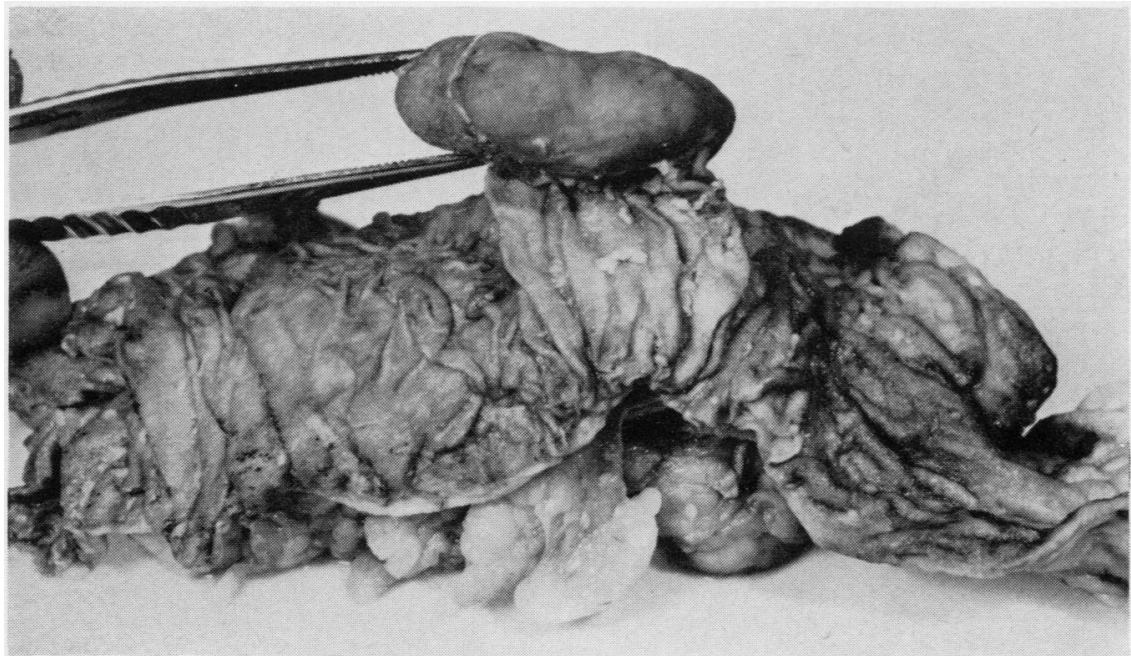

FIG. 2. Lateral view of the tumour which has been slightly raised to demonstrate the pedicle. $\times 2$. 


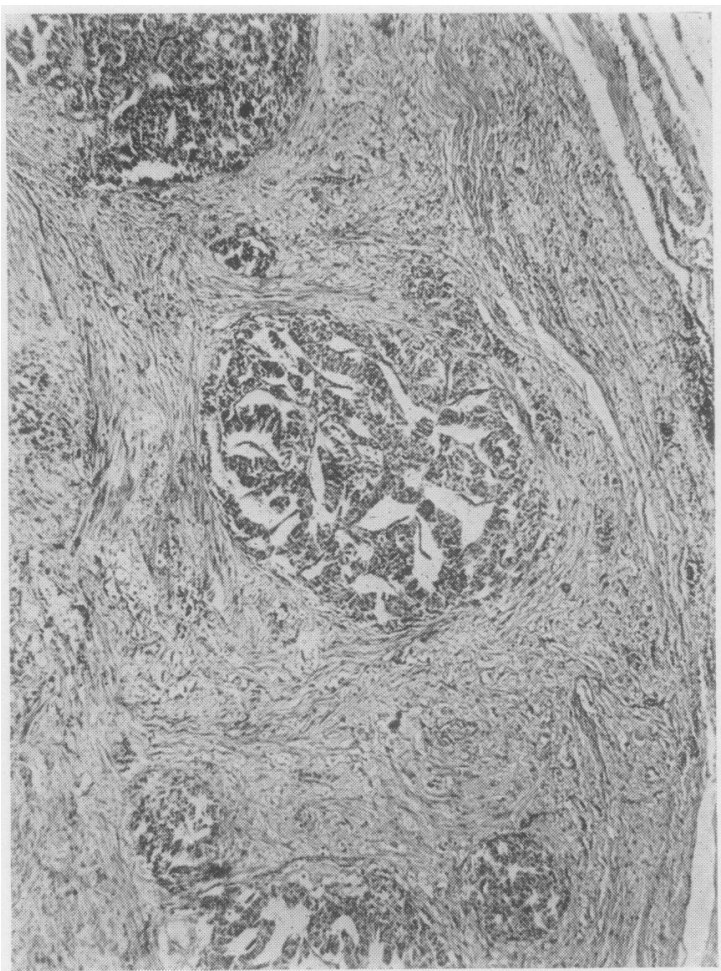

FIG. 3. Duodenal mass showing loose vascular connective tissue with rounded collections of cells. Haematoxylin and eosin $\times 80$.

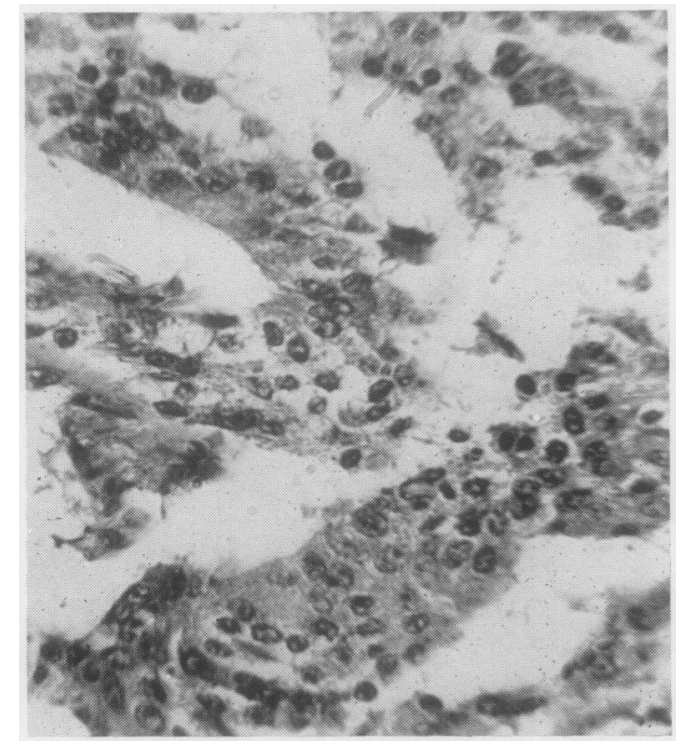

FIG. 4. Ribbon-like strands of cells forming the rounded collections of cells. Haematoxylin and eosin $\times 500$.
Heterotopic pancreas, that is pancreatic tissue an abnormal site, has been found in various organgs in the region of the pancreas and is one of the commonest forms of heterotopia. Heterotope pancreas is susceptible to all the diseases affecting pancreas as well as to complications which may. result from the presence of a glandular mass in abnormal site.

Islet-cell tumours arising in the wall of the duodenum have been described (Stewart and Hartfall, 1928; Holman, Wood, and Stockton, 1943; Porter and Frantz, 1956; Oberhelman, Nelsen, and Dragstedt, 1958), although none of these wege pedunculated tumours. Two pedunculated masses $\overline{\text { fif }}$ heterotopic pancreas in the stomach have been recorded (Leriche, 1929; Collett, 1946). Both of these produced pyloric obstruction and in the latter theire was prolapse into the duodenum. The tumow described here filled the transverse lumen of the bowel and it seems that obstruction would inevitably have occurred had the patient survived. It is possibse that the mobility of the tumour on its pedieke played a part in delaying obstruction. The retrof peritoneal situation of the second part of the du\& denum in which the tumour arose would prevent intussusception.

There were no clinical features in this case indicate any endocrine disorder produced by the tumour in spite of it being larger than most islet-ce्d̂1 tumours. In descriptions of this condition there has been no correlation between size and functiona status and a tumour as small as $2.5 \mathrm{~mm}$. in diameter has caused severe hypoglycaemia (Lopez-Kruger and Dockerty, 1947).

Death was due to myocardial infarction but the anaemia was undoubtedly a contributing factor. Sit is probable that the anaemia was due to blood loss from the ulcerated areas on the surface of the tumoinr as no other cause for the iron deficiency was found.

I am grateful to Dr. J. L. Edwards for helpful advice a⿳亠口冋, to Mr. D. Bradey for the histological preparations. The photographs were taken by the Photographic Departmeint of the United Sheffield Hospitals.

\section{REFERENCES}

Collett, R. W. (1946). Amer. J. Dis. Child., 72, 545 Pathology, Atlas Tumor Pathology, Sect. 7, Fasc. 2Z). Washington, D.C.

Holman, E., Wood, D. A., and Stockton, A. B. (1943). Arch. Su震, $47,165$.

Laidlaw, G. F. (1938). Amer. J. Path., 14, 125.

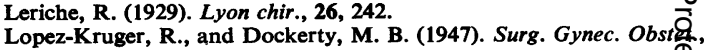

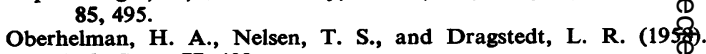
Arch. Surg., 77, 402.

Porter, M. R., and Frantz, V. K. (1956). Amer. J. Med., 21, 944. Stewart, M. J., and Hartfall, S. J. (1928). J. Path. Bact., 31, 137. 